\title{
34. Betrachtungen über die zytologischen Veränderungen in den in Kohlenteerlösung getauchten Wurzelspitzen junger Pflanzen.
}

I. Mitteilung. Nur für kurze Zeit eingetauchte Wurzelspitzen.

(a) Über das $7 \frac{1}{2}$ Min. lang behandelte Material (Vicia faba).

Von Komuro-Hideo.

(Rec. and Comm. by S. IKeno, M.I.A., March 12, 1931.)

Beobachtungen von $7 \frac{1}{2}$ Min. lang behandelten Vicia faba [Fève de marais grosse $(d u N o r d)$ ]-In die wasserausgeschiedene Kohlenteerlösung $\left(P_{H^{*}}=7.7-7.9\right.$ bei Neutralrot), die durch die Güte von Herrn Dr. P. Reiss in Strasbourg für mich hergestellt worden war, habe ich die Wurzeln der Keimlinge $7 \frac{1}{2}$ Min. lang (12-12.5.5 am 15. Feb., 1925) getaucht. (Nach kurzem Waschen mit Wasser wurden die Wurzelspitzen in Flemming (BeNDA) fixiert (Temperatur (C) : Zimmer 17'; Wasser $17.5^{\circ}$; Flemming $18^{\circ}$ ). Färbung: siehe diese Sitzungsberichte VI. Bd., S. 375 (Fußnote).

Der Hauptbefund ist wie folgt:

1) deutlich eosinophile Kerne sind in der Nähe des Vegetations: punktes und im größeren Teile des Plerom und des Periblem gefunden worden; dagegen waren die Kerne in den zwei oder drei Schichten der Zellstränge benachbart dem ", piliferous Layer " 1) und die in den Zellen der umgebenden Grenzschicht im Geweberaume basophil (Abb. 2),

2) Vakuolisierung des Zytoplasmas ist deutlich (Abb. 2),

3) eine ,"Gruppierungsveränderung chromatischer Substanz in dem hohl gewordenen Kerne " (Abb. 1/a), wie ich sie genannt habe, wurden häufig gefunden,

4) die Nukleolen sind tiefgefärbt mit Hämatoxylin, nehmen an Umfang zu und verändern ihre Gestalt,

5) mit der Vortritteilung (bei der Einschnürung) dieser basophilen, zunehmenden Nukleolen bilden sich aus dem eosinophil chromatolytischen Kern zwei Kerne durch den Einfluß zytoplasmatischer Vakuolisierung (Abb. 1/b), cf. unten Paragraph 10) mittels Entartung,

6) Gewebeabnormität entsteht durch Riesenzellbildung,

1) ScotT, Dukinfield Henry \& F. T. BRooks 1927: An introduction to structural botany. Part I, Flowering plants, $11^{\text {th }}$ ed., Lond., S. 76. 
No. 3.] Betrachtungen über die zytologischen Veränderungen usw.

7) Kernvakuolisierung war bemerkbar und dadurch hervorgerufene Kernwandhyperchromatose wurde sehr häufig beobachtet,

8) in den Kernen an der Vegetationspunktstelle fand man leichter verschiedene stärkere Degenerationsveränderungen als an anderen Stellen,

9)

Prophase

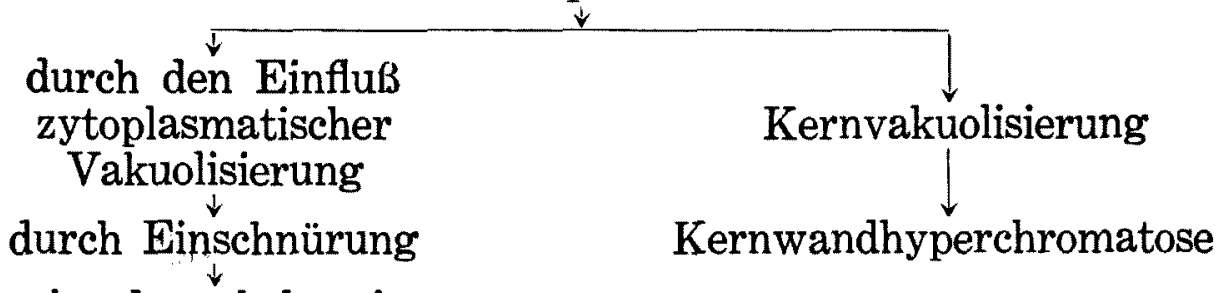

zwei- od. mehrkerniger

Zustand

10) Auffallend war:

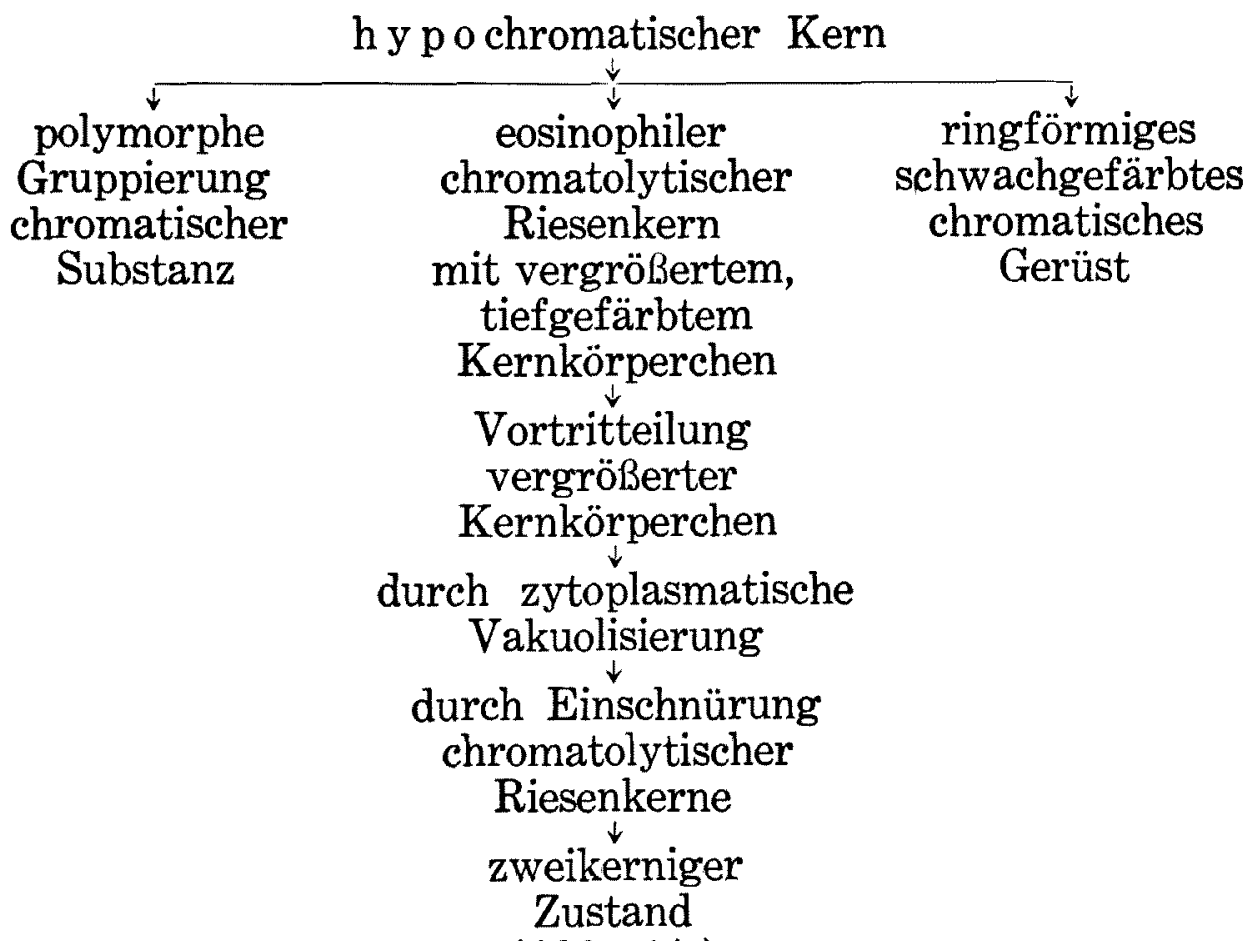

(Abb. 1/a)

11) Anschaulichen Befund ergab:

hy per chromatischer Kern

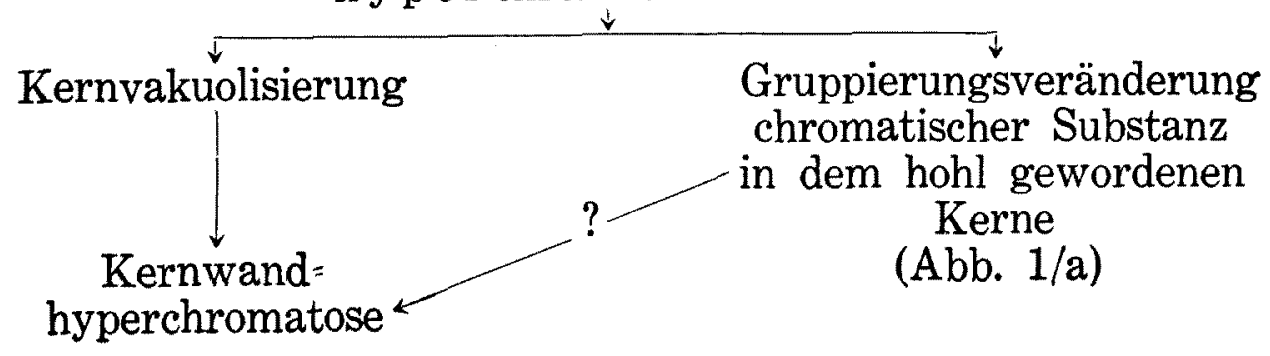


12) Kernteilungen waren sehr selten, und

13) präpyknotische Kerne wurden selten angetroffen.

\section{Erklärung der Abbildungen.}

Abb. 1/a. Eine Zelle mit Kern, der seine chromatische Substanz nahe an die Kernwand gruppiert hat, sodaB ein Hohlraum im Kerne entstanden zu sein scheint. Hiernach habe ich diesen Zustand als „Gruppierungsveränderung chromatischer Substanz in dem hohl gewordenen Kerne " benannt (2585/XXVIII II 12.0 ; Vergr. $2000: 1)$.

Abb. 1/b. Eine zweikernige Zelle im Plerom in der Nähe des der Vegetationspunkt= stelle benachbarten abnormalen Geweberaums. An dieser Stelle sieht man deutliche Vakuolisierung des Zytoplasmas, wie Abb. 2 zeigt.

Die Entstehungsursache dieser Zelle ist die in Paragraph 5) und 10) von mir vermutete. (Ebenda III 21.2 ; Vergr. $2000: 1$.)

Abb. 2. Großer Geweberaum und ein Teil des Plerom in der Nähe der Vegetations= punktstelle. Die Grenze des Geweberaums hat basophile Zellen bzw. Kerne. Zellen des Plerom haben vakuolisiertes Zytoplasma. Ihre Kerne sind deutlich eosinophil, unter ihnen findet man viele mit zweikernigen Zellen wie $\mathrm{Abb} .1 / \mathrm{b}$ (Ebenda III/14; Vergr. $320: 1$ ). 


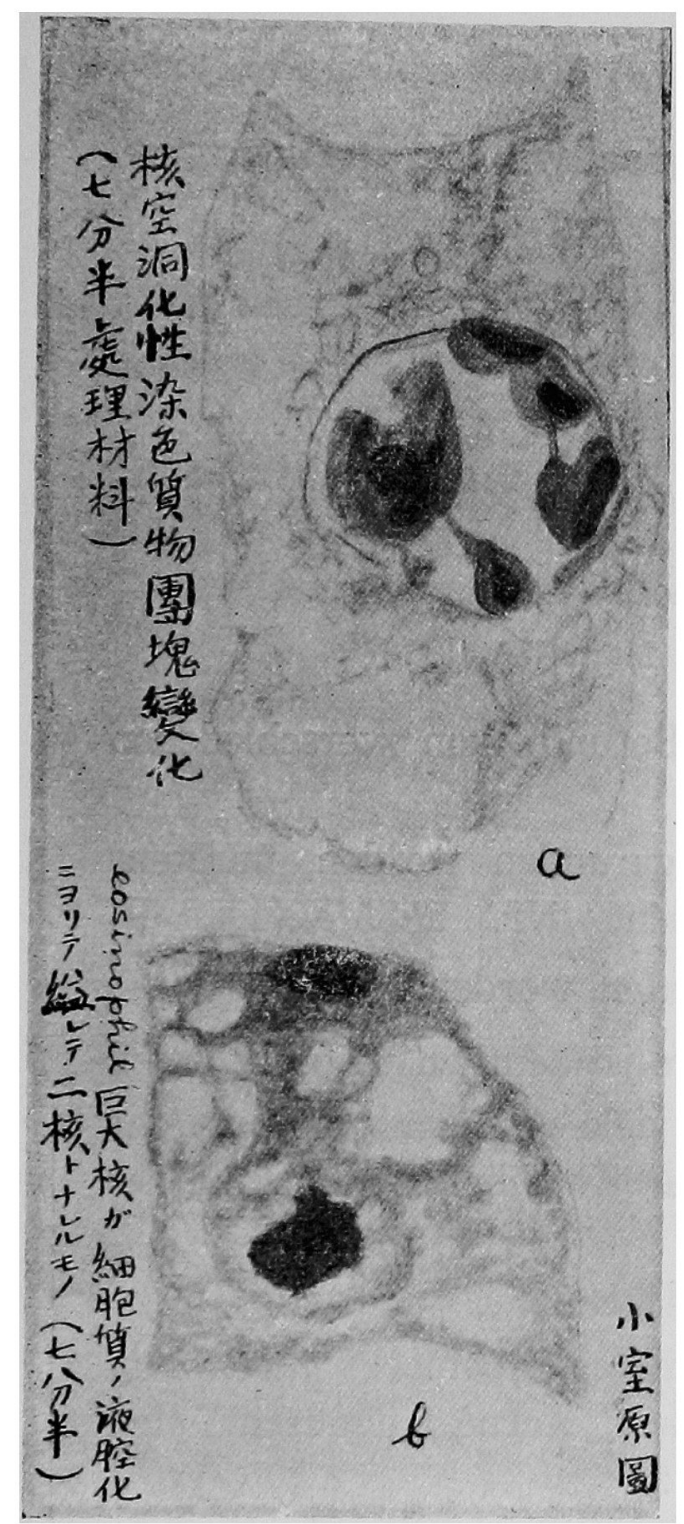

Abb. 1.

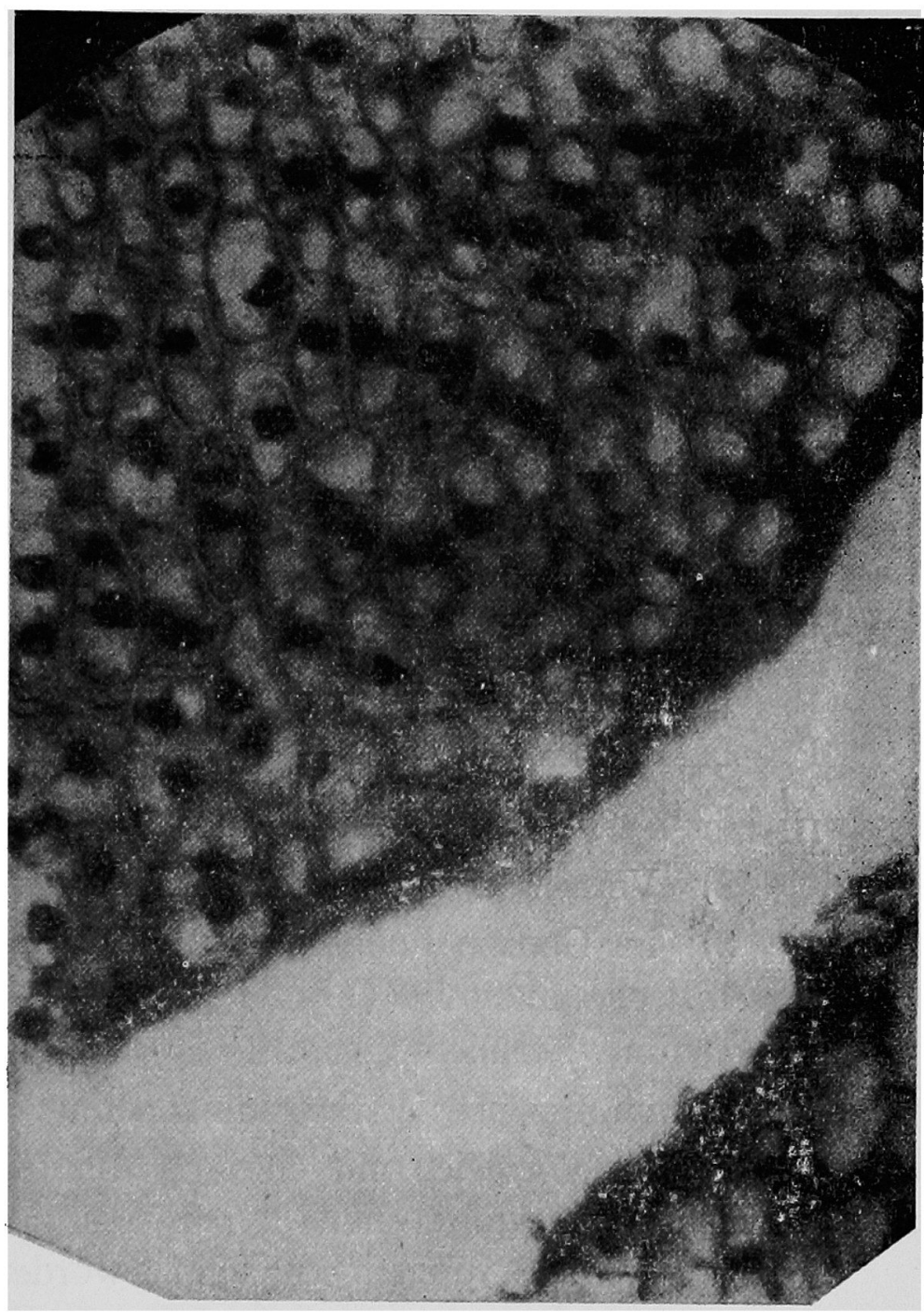

Abb. 2. 